\title{
ChInese Dynasties
}

$\begin{array}{ll}\text { Xia } & \text { 20th-15th century BCE } \\ \text { Shang } & \text { 15th century-1045 BCE } \\ \text { Zhou } & 1045 \text { BCE-256 BCE } \\ \text { Qin } & 221-207 \text { BCE } \\ \text { Han } & 206 \text { BCE-220 CE } \\ \text { Three Kingdoms } & 220-280 \\ \quad \text { Wei } & 220-265 \\ \quad \text { Wu } & 220-280 \\ \quad \text { Shu-Han } & 221-265 \\ \text { Jin } & 265-420 \\ \text { Northern and Southern dynasties } & 386-589 \\ \text { Sui } & 581-618 \\ \text { Tang } & 618-907 \\ \text { Five Dynasties } & 907-960 \\ \text { Song } & 960-1279 \\ \quad \text { Northern Song } & 960-1116 \\ \quad \text { Southern Song } & 1116-1279 \\ \text { Liao } & 907-1125 \\ \text { Jin } & 1115-1234 \\ \text { Yuan } & 1260-1368 \\ \text { Ming } & 1368-1644 \\ \text { Qing } & 1644-1911\end{array}$



THE PITFALLS OF PIETY FOR MARRIED WOMEN 
